\title{
Defining a Rule for the Use of Infinitive and Gerund Complements
}

\author{
Gregory Conti (Corresponding author) \\ Foreign Language Center of the University of Perugia \\ Via Errico dal Pozzo, 06100 Perugia, Italy
}

Tel: 39-340-612-5424Ｅ-mail: gregconti@fastwebnet.it

Received: March 3, 2011 Accepted: March 22, 2011 doi:10.5539/elt.v4n3p3

\begin{abstract}
This essay formulates a rule for the use of the to+verb and verb+ing finite complements designed to help students and teachers of English as a foreign language. The rule results from an analysis of the distinction between the directional function and inceptive aspect of the to+verb form, rooted in the prepositional origins of to, and the imperfective aspect of the verb+ing form, rooted in its use in the continuous tenses. Drawing on the work of, among others, Steven Pinker, Ekkehard Kônig, and Thomas Egan, these contrasting functions are clarified and reinforced by other uses of the to+verb form, such as the to be going to future and the to+verb subject or subject complement, and the use of the verb+ing form as a gerund, action nominalization, and deverbal adjective and preposition. The result of this comparative and relational analysis is a simple rule by which language learners can understand and effectively use the two complements correctly.
\end{abstract}

Keywords: Gerunds and infinitives, Finite complements, Foreign language acquisition

\section{Introduction}

Do you like skiing or do you like to ski? That certainly is not the question but it is $a$ question that foreign language learners of English often confront. Put another way, should I use the verb+ing complement or the to+verb complement? (Note 1) This essay argues that this question is most effectively answered by reference to a rule rather than memorization and formulates such a rule by examining the two complement forms and their aspectual relationships to their supporting main verbs, and by distinguishing between the directional function and inceptive aspect of the to+verb form, rooted in the prepositional origins of to, and the imperfective aspect of the verb+ing form, rooted in its use in the continuous tenses. The contention is that the to complement's origins in the directional preposition lead to its use to express an aspect of inception or transition from one action or state to a temporally or logically subsequent action or state, while the ing complement is used to profile the ongoingness of an action or state contemporary with or precedent to the action or state expressed by the main verb. (Note 2) Drawing on the work of, among others, Steven Pinker, Ekkehard Kônig, and Thomas Egan, these contrasting functions are clarified and reinforced by examining their relationship to other uses of the to+verb form, such as the to be going to future and the to+verb subject or subject complement, and the use of the verb+ing form as a gerund, action nominalization, and deverbal adjective and preposition. The result of this comparative and relational analysis is a simple rule by which language learners can understand and effectively use the two complements correctly.

\section{Words or Rules}

Steven Pinker (1999) has used the example of regular and irregular verbs to demonstrate that people learn language in two ways: words and rules. To form the past tense and past participles of regular verbs we apply a rule: look $>$ looked $>$ looked; bake > baked $>$ baked; study > studied $>$ studied while we have to learn irregular verbs by memorizing them as individual words: see-saw-seen; shake-shook-shaken; or (one of the real stumpers for verb learners unused to English's confused system of spelling and pronunciation), read-read-read.

Language learners, children and adults alike, learn language by using these two methods: learning and applying rules and memorizing exceptions to them. The faster learning curve of children, and the correspondingly slower curve of adults, are affected by how the two categories of learners learn the rules they have to apply. Take the rule that governs regular verb conjugation: the past tense and past participle are formed by adding $d$ or $e d$ to the infinitive. When children are learning English they learn that rule and learn to apply it without learning first how to state the rule. They hear people talking around them, identify the pattern, use it when they speak, and then adjust it when someone tells them they've made a mistake:

- Daddy, I seed a bluebird today. 
- No, Ben, you saw a bluebird.

- That's right, Daddy, that's what I telled you.

For adults learning a foreign language, the system is reversed. The student learns to recite the rule: The past tense for most verbs is formed by adding $d$ or ed, and then she learns to apply the rule to regular verbs. Then, of course, when she comes across a verb that falls outside of the category of "most verbs" she has to memorize it and a whole list of irregular verbs, maybe a hundred or so, depending on the grammar book. As hard as it is to remember a rule and apply it correctly, rules make language-learning much easier and more efficient and the older you get the truer that is.

\subsection{Gerunds and/or infinitives: words or rules?}

The words and rules dichotomy also comes into play for English learners and their teachers confronted with another arduous grammar point, the topic most grammar books refer to as "gerunds and infinitives." (Note 3) The label is a short-hand formula for those situations in which the object or complement of a verb is another verb, either in the to+verb (full infinitive) - He has decided to go to law school - or in the gerund or verb+ing form - She enjoys playing basketball. The hurdle for learners is determining which form to use after the main verb and the challenge for their teachers is how to help them get over the hurdle.

A survey of grammars and textbooks designed for learners of English as a second language seems to indicate that this is a word situation rather than a rule situation, and learning depends on memorization. (Note 4) Here is one explanation, more detailed than most, taken from an excellent book by the renowned scholar and teacher Ann Raimes $(1998,211)$ :

"19c. Infinitive as object. The infinitive can be used as the object of a verb. The problem is that some verbs are followed not by an infinitive but by a gerund (ing form). How can we tell whether to use an infinitive or an ing form? Some systematic organizing principles have been attempted, but they are complicated and full of exceptions. Probably the best thing for a language learner to do is to memorize the verbs that are regularly followed by either the infinitive or the -ing form and to keep lists of verbs that can take either according to context. So whenever you come across a verb followed by one or the other, write it down as it occurs in its sentence, and learn that particular use. This chapter and the next will provide you with some examples." The explanation is then followed by a list of fourteen verbs.

Now this certainly seems like helpful advice. Speaking for myself, however, as a teacher, I have tried innumerable times to memorize lists of verbs without success, so I find it hard to muster up much enthusiasm for encouraging students to use this method. The task becomes all the more daunting when you turn to the corresponding unit on -ing complements and find the same explanation and advice followed by another list of twenty different verbs (Raimes, 1998, p. 223)

Our list of verbs to memorize is now up to thirty-four items, and there are more to add because, as you may recall, there are some frequently used verbs that are followed by either the -ing form or the infinitive, sometimes, as Raines observes $(1998,224)$ "with a significant change in meaning, sometimes with a shade of difference so subtle that for most purposes you don't have to worry about it." This last comment may be reassuring to some learners but as a teacher I "worry about it" because Raines seems to be saying that it is the verb complement that changes, sometimes significantly, the meaning of the main verb. If that's the case, then I think she got it wrong; it's the different meaning of the main verb and, above all, its aspectual relationship (Note 5) to the complement situation that changes how it is to be complemented. But we'll address that issue later. For now, we should note that the commonly found items on lists of either/or verbs are:

$\begin{array}{lll}\text { remember } & \text { forget } & \text { try } \\ \text { stop } & \text { consider } & \text { imagine } \\ \text { hate } & \text { like } & \text { love } \\ \text { start } & \text { begin } & \text { continue } \\ \text { see } & \text { hear } & \text { feel } \\ \text { watch } & \text { notice } & \text { observe } \\ \text { mean } & \text { propose } & \text { regret } \\ \text { advise } & \text { allow } & \text { permit } \\ \text { recommend } & \text { intend } & \text { agree to }\end{array}$


be afraid bother claim

This list has twenty-eight entries, some of which are repeaters, but we are now in the ballpark of sixty verbs to memorize. Another prestigious book, A Practical English Grammar by Thompson and Martinet (1986, 214, 230, 234) also gives lists for the three categories - infinitive (48), gerund (38), and either (26) - for a total of 112 . It may well be that there's no way to define a rule to apply to all these cases but the prospect of memorizing sixty to a hundred verbs is certainly an incentive for trying.

\section{Question the complement rather than the verb}

In addition to the enormous amount of time and mental energy it requires, the memorization approach risks making learners focus on the wrong or less promising aspect of the problem. By focusing on the verbs rather than the complements, this approach encourages inquiries and analyses of the verbs themselves and comparisons between them. When students are shown a list of verbs that are followed by the full infinitive the obvious response is to wonder why that is the case. What do these verbs share that leads to that result? Are they all verbs of a particular aspect or duration or semantic meaning, for example, or are they verbs of mental state rather than verbs of action?

The possibility of identifying or defining a rule, even one with some exceptions, depends in large part on asking the right question, and given the large number of both verbs and verb types involved here, and the presence of verbs of just about every conceivable category on each of the three lists, it would seem more promising to start by questioning the verb complements rather than the verbs. After all, there are only two verb complements to choose from here: verb +ing and to +verb. Perhaps by comparing them, their forms, their position and function in other grammatical structures, and especially their aspectual relationship to the main verb, we may be able to identify a rule that describes their differing uses as verb complements.

\section{What's in a name?}

Readers will have noticed that Raimes refers to these two complements as the -ing form and the infinitive while I have just labeled them as verb+ing and to+verb. My hope is that this difference in nomenclature will be helpful in developing a rule. First, this way of indicating the two forms allows us more easily to see what the forms have in common (the root verb) and what different (ing vs. is to). It also allows us to eliminate the discrepancy in naming one form after the letters which compose its ending (ing) and the other by a noun (infinitive) denoting a verb unattached to some finite subject or time. Another advantage of using to+verb is that we can avoid the confusion engendered by the multiple names by which this form is indicated by grammarians: infinitive, to infinitive, to +infinitive, full infinitive (as opposed to the bare infinitive or the infinitive without to), infinitival, to + plain form, and there may be others. Finally, the most convincing reason for using the label to+verb is that it reminds us that to exists in its own right as a preposition.

\section{The preposition to: direction in space, time, and logical sequence}

As Rodney Huddleston has noted $(2002,1241)$ " $t o$ derives historically from the homophonous preposition to and . . certain aspects of its infinitival subordinator use reflect its origin. Prepositional to is characteristically associated with a goal, and a metaphorical association between to-infinitivals and goals is to be found in the fact that they commonly involve temporal projection into the future, as with the complements of ask, choose, consent, hesitate, order, persuade, promise, resolve, strive, tell, threaten, and countless other catenatives." (Note 6)

Huddleston's observation provides solid support for the proposition that the use of the to+verb complement is related to the origins of to in the preposition of the same spelling and sound, indicating movement not only in space but in time. (Note 7)

It may also be useful to note that to as a preposition indicates both direction and destination, making it the mirror image of its twin from, which indicates direction and point of departure. The terminal element of to is further evidenced when it becomes part of the adverb toward. When something moves toward, it moves in the direction of some explicit terminal point and in most examples of the to complement that terminal point is in the future with respect to the main verb. (Note 8)

Further support for this directional nexus between the preposition to and the to+verb complement comes from two other grammar topics which language students are accustomed to confronting in progressively greater depth as they move up the skill levels from beginners to intermediate to advanced: the to be going to+verb form to make the future tense and the to+verb form used as a subject or subject complement.

\section{The grammaticalization of going to}

The going to + verb future form illustrates Huddleston's point about the metaphorical connection achieved through use of the preposition to between movement toward a destination in space and movement toward a destination in time. This is easy to see in the following example: 
(1) We're all going to the club tomorrow and Phil and Kate are going to play tennis.

The first use of going to is the present continuous form of the verb go (are going) and the preposition to indicates the direction of the movement through space toward a destination (the club). The second going to, however, is the future of play and the going to is used to indicate the direction of movement through time toward a future action (play). In other words, in this second use of going to, the phrase loses its original semantic meaning of physical movement to become a grammatical marker of future time. Furthermore, this metaphorical going to has acquired its own special form, gonna, which is used only to mark future time. English speakers do not say We're gonna the club but they do say We're gonna play tennis. Grammarians have labeled this phenomenon grammaticalization. (Note 9)

Egan $(2008,95)$ reminds us that gonna is one of four grammaticalizations of to, the others being hafta (have to), wanna (want to), and gotta (got to), where wanna projects a desire toward another state or action, and hafta and gotta project an obligation toward another state or action. (Note 10) Interestingly, however, the obligation projected toward the complement situation by hafta or gotta (and sometimes even the desire projected by wanna see example (22) below) is not necessarily projected into future time. The obligation and its fulfillment may be contemporary with the state of obligation.

A clear and entertaining example of this can be seen in the musical Singin' in the Rain. In the scene known as the Broadway Rhythm Ballet, when Don Lockwood (played by Gene Kelly in the film) and the chorus line launch into singing "Gotta dance," they are in fact already dancing. (Note 11) In the grammatically correct, somewhat less snappy full-sentence version of the lyric, I have got to dance, the main verb have got expresses the speaker's feeling of obligation toward the already initiated activity of dancing, profiled in the complement to dance. The projection expressed by to in the to+verb complement, therefore, need not be a forward projection in time but to nevertheless projects the obligation toward the targeted alternative of dancing.

\section{The to+verb complement as a present targeted alternative}

To further illustrate the use of the to+verb complement to indicate a present targeted alternative rather than a future projection we can examine an example taken from Strutt $(2000,43)$ :

(2) She claims to have the authority to proceed.

In this case, there is clearly no forward projection in time of the complement to have with respect to the main verb, claims; the person making the claim either has or doesn't have the authority at the same time she claims to have it. In fact, it is safe to assume that she had or believed she had the authority even before she voiced her claim to it. Nevertheless, there is a kind of directional relationship between claiming and having that is expressed by to. We may be able to see that relationship better by looking first at another example:

(3) Homesteaders had to stake a claim to the land before occupying it.

Here the noun claim - an assertion of ownership - takes the form of a wooden stake driven into the ground, thus giving physical form to the assertion of ownership, and the preposition to indicates the direction of the claim. It is an assertion of ownership that goes in the direction of the land. Likewise, in our previous example (2), where claims is the verb, to indicates the direction of the speech-act of claiming toward the state of possession, expressed by the verb have. What we have here then is not a temporal projection but what we might call a logical projection.

A similar kind of non-temporal logical projection is performed by the to+verb complement in the following examples:

(4) Susie failed to see the point.

(5) Ann refuses to accept the fact that her husband is guilty.

(6) If they work at it they will manage to reach their objective.

(7)I want to eat my ice cream.

In examples (4-7), there is no forward projection in time between verb and complement. In fact, in the first two examples the action expressed by the complement does not and could not actually take place. Otherwise the sentence would not make sense. What the to expresses here is the direction of the failure and the refusal, or perhaps we might think of it as the direction of the effort made or of the consideration given leading up to the moment of failure and refusal. This kind of logical direction is even more evident in the third example. When you manage or don't manage to do something there is no separation in time between manage and do (or reach). The verb manage to expresses both effort and success (or in the negative effort and failure) and in both cases, the to complement indicates the direction of the successful or unsuccessful effort. In (6), they will make an effort in the direction of reaching their objective and that effort is likely to succeed. 
The last example (7), want to eat, involves not effort but a desire to do something. The relationship between verb and complement might be conceived as a forward projection in time, however brief, but this is not necessarily the case. The speaker may simply be expressing the present focus of his desire rather than a present desire projected toward a future action. That is, there may be no temporal difference between this sentence and the sentence I want my ice cream. There is, however, a logical projection of the desire (expressed by want) toward the action of eating.

This projection becomes clearer if we broaden the context. Imagine that the speaker is at home in the kitchen and has just prepared himself a bowl of ice cream. His wife comes in the kitchen and tells him that she's about to go do the shopping, gives him a series of options as to what she could buy for dinner, and asks him What do you want? To which he responds I want to eat my ice cream, leaving unstated I don't want to think right now about the shopping or what we're going to have for dinner. In other words, the speaker is indicating the focus or direction of his present desire or preference. (Note 12)

In his wide-ranging analysis of what he calls the to infinitive complement, Egan $(2008,97-98)$ takes a similar approach to the one I have been trying to develop here. Egan defines three categories of to complement situations: "Forward-looking constructions," "General constructions" and "Judgement constructions," which he defines respectively as:

"a situation, viewed as a whole, is profiled as expected, but not certain, to occur at some remove in the future from the matrix verb";

"a situation, viewed as a whole, is profiled as likely to occur on a more or less regular basis";

"a situation, viewed as a whole, is hypothesized to be true." (13)

What seems to distinguish "general" and "judgement" constructions from "forward-looking" constructions is the "domain" in which the projected complement is realized. In "forward-looking" constructions the complement is projected forward in time, into the domain of the future, while in "general" constructions the complement is profiled as likely to be realized in the domain of "suitable occasions in the past present, and future," where "suitable occasions" are those where the appropriate or necessary conditions for the realization of the complement situation are present, and in "judgement" constructions the domain in which the most likely alternative is realized is the subject's mind/opinion/view etc. (Egan 2008, 97-99). But while these three constructions are in some ways different, they all have in common the sense of direction and destination that is inherent in the preposition to, a sense which Egan condenses in the felicitous phrase "targeted alternative": "The to infinitive encodes a targeted alternative. .."(99). The alternative that is targeted by to is usually projected forward in time relative to the main verb. Egan's "forward-looking" constructions, in fact, account for $77 \%$ of the to infinitive complements in his sample. But, as we have seen in our examples, the targeted alternative may also be contemporaneous with or even prior to the main verb to the extent that the targeted alternative action to be taken or not taken on the "suitable occasions" profiled by "general" construction may also have been situated in the past or the present with respect to the main verb.

\section{To+verb as subject and/or subject complement: goal or transition}

At this point, we have been able to explain the use of the to+verb complement in a variety of examples, all involving a forward projection in time or a psycho-emotional or logical projection with respect to the main verb. This projection effected by to could be the basis on which to construct our rule, and starting from that hypothesis we will move on to examine the use of the ing complement to see if and how it might be distinct from its to counterpart. A valid rule must be able to explain the use of both alternatives as well as those cases in which either can be used.

Before moving on to ing, however, it will be helpful to examine another aspect of the to+verb complement and that aspect is aspect. It will be recalled that in his definitions of the three categories of to complements, Egan refers to what might be termed their aspect of wholeness: the complement situation is "viewed as a whole." This characterization is certainly valid and supported by the examples from Egan's corpus but I believe it is incomplete. It is my contention that the aspect of the to+verb complement is both whole and inceptive, that is, the complement situation is "viewed as a whole" but the focus is on its initial phase or inception, on the moment of passage from the main verb to the complement verb to which the main verb is directed by to. The inceptive aspect of the to+verb complement is reflected in the use of the to infinitive as a subject or subject complement. (Note 14)

As Ann Raimes points out (1998, 209-210), the to infinitive, as she calls it, can also be used as a subject or a subject complement as in the examples:

(8)To succeed is his goal, above all else.

(9)His aim is not to make one mistake. 
Both of these examples involve forward-looking situations and so the use of the to+verb form seems to square with our hypothesis. But it is really not possible to have a goal or an aim that is not projected into the future. Otherwise, they would either have already been realized or not, thus losing their status, in the present, as goals or aims that might still be achieved or fail to be achieved. So to better test the hypothesis it may be helpful to look at a less obvious example.

In the 1950s, songwriter Phil Spector wrote a song entitled "To Know Him is to Love Him." The song was subsequently recorded by some famous singers - Peter and Gordon, Bobby Vinton, and the Beatles (Note 15)under the title

\section{(10) "To Know Her is to Love Her."}

Regardless of the gender change of the object, the title features the to+verb construction as both subject and subject complement and in both cases the form suggests an inceptive aspect, that is, a transition from one state (not knowing and not loving) to a subsequent state (knowing and loving). Put another way, love does not exist without knowledge: once you know her you're bound to love her. But the converse is also true: if you haven't met or don't meet her you can't or will not be able to love her.

The same kind of transition between states is most famously expressed in what must be the best known and most often recited question in English:

(11) To be or not to be?

Perhaps the first thing to note is that Hamlet's query poses a false choice. The one thing none of us can choose is $t o$ $b e$. The best we can do is try to make the most of our being and, failing that, perhaps consider choosing not to be. Indeed, as the rest of his speech makes clear, Hamlet is contemplating suicide, that is, the passage from a state of living (being) to a state of not living (not being). To sharpen our understanding of the inceptive aspect of to be and not to be we need only replace the two phrases with the ing form. Could Hamlet have proclaimed: Being or not being, that is the question? No, because in that case he would not have been contemplating a transition between two states but a choice between two ongoing states (life or death) rather than a transition from one state to another. Like the use of to in the going to future, therefore, the use of to+verb as a subject or subject complement also seems related to the forward-projecting function and inceptive aspect of the preposition to.

\section{Verb+ing: ongoingness or action nominalization}

Our focus now shifts to the verb+ing form to see if we can identify one or more common threads that tie it to other uses of the ing form and that may distinguish its use as a verb complement. The German scholar Ekkehard Kônig, has identified eight uses of the ing form (Note 16):

(12) This is very interesting (deverbal adjective)

(13) I am not talking to you. (progressive aspect, past, pres. future)

(14) We risked getting caught. (gerund) Reading poetry enriches your life.

(15) Walking along the river, I suddenly saw a crane. (adverbial participle)

(16) The guy talking to George is my boss. (non-finite relative clause)

(17) No reading of poetry is good enough for Mary. (action nominalization)

(18) California is a real melting pot. (nominal compound)

(19) Concerning your recent proposal, I think ... (deverbal preposition)

Of the eight uses identified by König, four are verbs or adverbs or verb derivatives:

is interesting - deverbal adjective

am not talking - progressive tense

walking along the river - adverbial participle

concerning your proposal - deverbal preposition;

and they all express a sense of progressivity, or ongoingness.

These four verbal or verb-derived ing forms share the function of what we might call describing or setting the scene for a narration or sequence of events, of telling us what is, was, or will be happening or ongoing at a certain moment in the present, past, or future. 
The other four uses: gerund, action nominalization, nominal compound, and non-finite relative clause are nouns or noun derivatives and as such they are not placed in time or are placed in time by the main verb, rather than by the -ing suffix. While the nominative function of the ing form is dominant in these four uses, they nonetheless maintain some of the flavor of an ongoing action, as we can see if we replace them with non -ing synonymous nouns:

(20) We risked capture.

(21) George's interlocutor is my boss.

(22) No interpretation of poetry is good enough for Mary.

(23) California is a real crucible.

In all of these examples, the unfolding, dynamic aspect expressed by the ing form has been lost and the object of the verb has a static quality.

There appear to be two common features in Kônig's examples of the -ing form: 1. a nominative function that could be labeled, as Kônig calls it, an action nominalization and 2. a progressive, or ongoing or, if you will, imperfective aspect, as opposed to inception or sequence or forward projection. This imperfective aspect of the -ing form is undoubtedly rooted in its use to form the progressive verb tenses, as we will discuss in more detail below.

\section{Testing the either/or verbs}

If the use of the -ing form as a verb complement is related to these other eight uses, then we should be able to identify one or both of these characteristic features in the verb+ing complements. Perhaps the most effective way of testing this hypothesis is to look at Raimes' examples of verbs that can take either the to+verb or the verb+ing complement.(1998, 224-225)

remember/forget

(24) She remembered to mail the letter

(25)She remembered mailing the letter.

In (24) the mental act of remembering happens first and is projected forward to the subsequent action of mailing the letter. In (25) the mental act of remembering happens subsequent to the act of mailing, which is recalled as a nominalized action-in-progress at a moment in the past.

try

(26) She tried being more forceful.

(27) She tried to be more forceful.

In (26) she experimented with or adopted on an ongoing basis a new more forceful behavior. In (27) she made an effort toward the adoption of more forceful behavior.

consider/imagine

(28) He is considering running for office.

(29) I can't imagine speaking in front of 500 people.

In (28), running for office would most likely be understood as a future ongoing activity with respect to the time of considering but that is not necessarily the case. Suppose the speaker is referring to a political scientist who is researching the process of running for office. In any event, running for office seems to be a nominalized action-in-progress here; his considering could be projected toward the future but may not be. In (29) it seems much clearer that the speaking is not placed in time but is the name of the action or the image of the action as it is unfolding in a certain context.

(30) People consider him to be very competent.

(31) I don't imagine him to be a good public speaker.

These are both what Egan calls "Judgement" constructions. In both of these examples the complement is not projected forward in time but the to does express the destination or the direction in which the mental attitude is projected. Notice that the -ing form might also be used in the second example: I don't imagine him being a good public speaker in which case the focus shifts from the direction of the speaker's imagining to the ongoing or enduring aspect of the complement.

hate, like, love

(32) I hate smoking. 


\section{(33)I hate to smoke.}

In the first example, the speaker hates the imperfective activity or behavior of smoking, regardless of who is doing it or when. In the second example her emotion is directed toward her own performance of the activity and to her passage from the state of not smoking to smoking.

(34)I love/like watching tennis.

(35)I lovellike to watch tennis.

Most English speakers would probably agree that they use these forms interchangeably or that they would not normally distinguish between them. Nevertheless, it is more likely that the speaker would use (34) to express her preference for the unfolding activity of watching tennis wherever and whenever she may do that while it is more likely that she would use (35) to indicate the activity to which her preference is directed in certain conditions or, to use Egan's formulation, on some "suitable occasion." (Note 17)

(36) What do I do to relax? I love watching tennis.

(37)I love to watch tennis in the winter but in the summer I love to play.

This distinction also seems to guide native English speakers in their use of to and -ing complements with the verb prefer.

(38) Generally, I prefer going to a movie over watching TV but right now I prefer to watch TV.

In his analysis of prefer, Egan $(2008,183)$ emphasizes the aspectual difference between the two complement constructions: The difference between the two prefer constructions is not as great as it is in the case of positive and negative attitude constructions [like, love, adore, hate, loathe, detest]. Nevertheless, a difference there is... On the one hand [prefer +to+verb] a process is viewed as a whole from a distance as the targeted option; on the other [prefer + -ing] it is construed from within as it unfolds before our eyes."

start, begin, continue

\section{(39)She started/began writing the report this morning.}

(40) She started/began to write the report this morning.

Here again, either version would be acceptable in most situations. The interchangeability of the two complements may have to do with the strong sense of inception that is already expressed by start and begin, overshadowing the inceptive aspect of to. My guess, however, is that if the speaker were responding to a query about when the report would be finished (that is, a question posed when the writing is still in progress) he would be more likely to respond with the -ing complement, whereas if the query were focused for some reason on the inception of the act of writing, he would more likely respond with the to complement.

(41) So when will the report be ready? Probably tomorrow, he started writing it this morning.

(42) So what did he do when you told him that if the report is late he risks losing his job? He started to write the report.

Raimes doesn't give us examples for continue so let me propose a pair.

(43) She started writing at five in the afternoon and continued writing on into the night.

(44) She started to write novels when she was six and continued to write them until she died.

Again the two complements could be used interchangeably. Nonetheless, I think it's fair to say that the use of ing in the first example emphasizes the uninterrupted, unfolding aspect of a single action while the to complement in the second example makes it easier to envision a series of actions with the inception of the next one following the completion of the preceding one, an emphasis on repeated transitions from not-writing to writing. (Note 18)

\section{Conclusion}

At long last we may be in a position to formulate a rule that can guide learners of English in determining whether to use the to +verb form or the verb+ing form as a complement to the main verb:

When the context calls for a complement that is projected forward in time with respect to the main verb or that directs the force of the main verb toward an inceptive alternative action or state, use the to+verb form. Otherwise, use the verb+ing form.

This rule focuses the learner's attention away from the main verb and toward the temporal and aspectual relationship between the main verb and the verb complement. Furthermore, it accounts for the use of the two forms with respect to the main verbs included in the three lists (to, ing, either) proposed by most grammar books, and it also seems 
consistent with the forward-projecting role of to in the to be going to future as well as the inceptive aspect of the to infinitive used as a subject or subject complement. At the same time, the rule is consistent with the function of the -ing form in the eight uses described by Kônig and with the three categories of to complement situations described by Egan.

The effectiveness of the rule as a tool for language learning/teaching will have to be tested in the classroom. At first glance, it seems safe to wager that, like other rules, it will be more immediately useful in the acquisition of passive skills (reading and listening) by helping learners first to understand how and why the various infinitival complements are used by writers and speakers of English. By the same token, it should be of assistance to translators and interpreters in finding forms to express in other languages what is communicated by the complements in English. But all language skills are interrelated and mutually reinforcing and if the rule is effective for some skills it will be effective for all of them. At the very least, it is undoubtedly true that the rule, for all its underlying complexity, is much simpler and easier to learn and implement than the alternative of memorizing long lists of verbs. Beyond that, the rule has the added advantage of being logically related to other uses of the infinitive and -ing forms and of fitting into a pattern of aspectual relationships that are present throughout the grammar of English. In other words, the rule is something that a language learner can figure out and that, once learned, will reinforce her understanding of, to use Raimes' brilliant book title, "how English works." At this juncture it would be too much to claim that there are no exceptions to the rule. Perhaps what we have come up with is only a rule of thumb but for language learners a rule of thumb is certainly better than no rule at all.

\section{References}

Bailey, David. (1992). "The problem of the alternation of to V/V -ing after 'aspectual' verbs", in: J. Chuquet and D. Roulland (eds.), Subordination, subordinations. Rennes: Presses Universitaires de Rennes II. 185-197.

Bladon, R.A.W. (1968). 'Selecting the 'to' or 'ing' nominal after 'like, love, hate, dislike,' and 'prefer'”, English Studies, 49:203-214, doi:10.1080/00138386808597300, http://dx.doi.org/10.1080/00138386808597300

Conrad, Bent. (1982). Referring and non-referring phrases: a study in the use of the gerund and the infinitive. Københaven: Akademisk Forlag.

Dirven, René. (1989). “A cognitive perspective on complementation,” in D. Jaspers, W. Klooster, Y. Putseys, and P. Seuran (eds.), Sentential complementation and the lexicon: studies in honor of Wim de Geest. Dordrecht: Foris. 113-139.

Duffley, Patrick J. (1992). The English Infinitive. London: Longman.

Duffley, Patrick J. (1999). "The use of the infinitive and the -ing after verbs denoting the beginning, middle and end of an event," Folia Linguistica, 33: 295-331, doi:10.1515/flin.1999.33.3-4.295, http://dx.doi.org/10.1515/flin.1999.33.3-4.295

Duffley, Patrick J. (2000), 'Gerund versus Infinitive as Complement of Transitive Verbs in English', Journal of

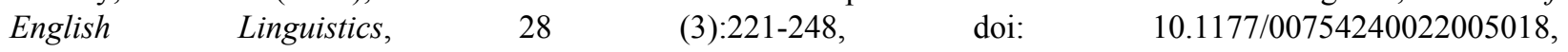
http://dx.doi.org/10.1177/00754240022005018

Duffley, Patrick J. (2003), 'The Gerund and the to-infinitive as Subject', Journal of English Linguistics, 31 (4):324-352, doi:10.1177/0075424203257833, http://dx.doi.org/10.1177/0075424203257833

Duffley, Patrick J. (2004). 'Verbs of Liking with the Infinitive and the Gerund", English Studies, 85: 358-380, doi:10.1080/00138380412331339158, http://dx.doi.org/10.1080/00138380412331339158

Duffley, Patrick J. (2006), The English gerund-participle: a comparison with the infinitive. New York: Peter Lang.

Egan, Thomas. (2008). Non-finite Complementation: Amsterdam - New York: Editions Rodopi B.V.

Fischer, Olga. (1997). "The Grammaticalization of Infinitival to in English compared with German and Dutch," in Hickey, Raymond and Stanislaw Puppel (eds.) (1997). Language History and Longuistic Modelling: a Festschrift for Jacek Fisiak on his $60^{\text {th }}$ Birthday. Berlin: Mouton de Gruyter.

Fischer, Olga, Ans van Kemenade, Willem Koopman, Wim van der Wurff. (2000). The Syntax of Early English. Cambridge: Cambridge University Press.

Fischer, Olga. (2003). "Principles of grammaticalization and linguistic reality," in: G. Rohdenburg and B. Mondorf (eds.), Determinants of Grammatical Variation in English. Berlin: Mouton de Gruyter. 445-478.

Freed, Alice F. (1979). The semantics of English aspectual complementation. Dordrecht: Reidel. 
Huddleston, Rodney, (2002). "Non-finite and verbless clauses," in R. Huddleston and G.K. Pullum (eds.) The Cambridge Grammar of the English Language. Cambridge:Cambridge University Press (1171-1272)

Kônig, Ekkehard. (1990). Adverbien und Partikeln. Heidelberg:Groos.

Pinker, Steven. (1999). Words and Rules: The Ingredients of Language. New York: Basic Books.

Raimes, Ann. (1998). How English Works. Cambridge: Cambridge University Press.

Strutt, Peter. (2000). Market Leader Business Grammar and Usage. Essex: Pearson Education Limited.

Thompson, Audrey Jean \& Martinet, Agnes V. (1986). A Practical English Grammar. Oxford: Oxford University Press.

Verspoor, Marjolijn. (1990). Semantic Criteria in English Complement Selection, Ph.D. dissertation. University of Leiden.

Verspoor, Marjolijn. (1997). "The story of -ing: a subjective perspective," in M. Pütz and R. Dirven (eds.), The Construal of space in language and thought. Berlin: Mouton de Gruyter, 417-454.

Verspoor, Marjolijn. (1999). “To infinitives,” in: L. De Stadtler and C. Eyrich (eds.), Issues in cognitive linguistics: 1993 proceedings of the International Cognitive Lingusitics Conference. Berlin: Mouton de Gruyter. 505-526.

Verspoor, Marjolijn. (2000). "Iconicity in English complement constructions: conceptual distance and cognitive processing levels," in: K. Horie (ed.), Complementation: cognitive and functional perspectives. Amsterdam: John Benjamins. 199-225.

Wierzbicka, Anna. (1988). The semantics of grammar. Amsterdam: John Benjamins.

Wood, FrederickT. (1956). 'Gerund versus infinitive' English Language Teaching, 11:11-16.

\section{Notes}

Note 1 . The question can also be extended to the bare infinitive and the to +verb+ing complements but these are less frequent and generally less problematic for foreign learners of English and are not treated here.

Note 2. As will be seen in section 5.0, the verb+ing complement is also but less frequently used to refer to complement situations located in the future with respect to the matrix verb but even in such cases the ing complement confers a durational, imperfective, and /or ongoing aspect to the complement situation.

Note 3. A more scientifically effective name for this grammar point is the title of Thomas Egan's book, Non-finite Complementation (Rodopi, Amsterdam, 2008).

Note 4. Azar (1992), see chapter 10 "Gerunds and Infinitives," pp. 246-275, Beaumont and Granger (1989), see units 81-100, Hewings (2005), see units 30, 31, pp. 20-63, Murphy (1994), see units 52-60, pp. 104-121, Naunton and Hughes (2009), see "Grammar Guide" for unit 9, "Gerund and Infinitive," pp. 174-175, Norris (2008), see "Grammar Reference" section for unit 2 "Gerunds and Infinitives," pp. 206-207, Strutt, Peter (2000), see unit 6, pp. 40-46, Swan (1980), see section 322 "Infinitive after verb" and section 334 "-ing form after verb," Thompson and Martinet (1986), see chapters 23, 24, 25, pp. 212-238, Vince (2003) see unit 28 "verbs followed by -ing or infinitive," pp. 164-169.

Note 5. Support for the notion that the pertinent element in complement selection is the relationship between the matrix verb and the complement rather than the semantic category of the matrix verb is to be found in the works of M. Verspoor $(1990,1997,1999,2000)$. As Verspoor explains, "What is pertinent is the relationship between the matrix subject and what is stated in the complement. Of course, the lexical content of a matrix verb (semantic category) has something to do with establishing this relationship. But by using different complement structures, we can express differences, mainly to do with direct involvement, in this relationship." Verspoor (1999, 509-512).

Note 6. In his summary of the scholarship on non-finite complementation, Egan, citing Fischer (2003), Bailey (1992), Duffley (1992) states plainly and forcefully that "There is a broad consensus among scholars that the to of the infinitive is historically derived from the preposition to." Egan $(2008,95)$

Note 7. That the infinitival to expresses forward direction in time as opposed to prepositional to's forward direction in space, is underlined by Duffley: "the potential meaning of to before the infinitive is more abstract than that found in the spatial use of the preposition, and can be stated as follows: the possibility of a movement from a point in time conceived as a before-position to another point in time which marks the end-point of the movement and which represents an after position with respect to the first" (Duffley 1992:16) quoted in Egan $(2008,95)$. 
Note 8. Perhaps the strongest statement of the thesis associating the to complement with future projection was made by Wierzbicka $(1988,165)$ : "In most types of TO complements which have been discussed here there is also a clear future orientation. . . and there is reason to think that this feature, too, should perhaps be regarded as part of the semantic invariant of all TO complement constructions. Duffley (1992) also subscribes to the futurity thesis. Egan $(2008,62)$ puts it this way: "According to Duffley there is always some element of futurity (vis-à-vis the matrix verb) involved in the use of the to infinitive." While conceding that the majority of to constructions are forward-looking constructions, Egan denies that futurity is always present in to complements and, as will be seen, I share his dissent on this point.

Note 9. Fischer, Kemenade, Koopman, Wurff (2000). See especially pp. 286-288 where the going to>gonna transformation is treated in detail.

Note 10. Olga Fischer has studied the grammaticalization of the English to in relation to similar processes undergone by the Dutch te and the German zu. See, for example, "The Grammaticalization of Infinitival to in English compared with German and Dutch," (Fischer, 1997).

Note 11. A brief glimpse of what has been called the most thrilling dance number ever staged can be seen in the trailer for the film at http://www.spike.com/video/trailer/2672755.

Note 12. In his book The English Infinitive, Duffley takes the position that the to+verb form consists of a combination of a form of the preposition to and the infinitive proper or, as I prefer to call it, the simple form of the verb, and in Duffley's interpretation this combination always connotes a relationship of futurity between the matrix verb and the complement verb. Duffley's forward-looking conception of the to+verb form has remained unchanged in his more recent studies $(2000,2003,2006)$.

Note 13. As an example of a general construction, Egan uses, among many others, "When we are hungry we love to eat bread" (ex. 187, 97) and one of his examples of a judgment construction is "Trent had been correct in guessing their destination to be on the north fork of the Belpan River" (ex. 192, 97).

Note 14. Several scholars, including Wood (1956) and Dirven (1989) have discussed the distinction between the to +verb and -ing subject in terms of particularity (to +verb) versus generality (-ing) but corpus studies by both Duffley (2003) and most recently Egan (2008) have rejected this distinction. Duffley writes, "One obvious observation revealed by the study of the corpus is that there is no significant difference between the gerund and infinitive as to their capacity of expressing particularity or generality" (2003:335).

Note 15. The Beatles version (recorded when they were known as the Silver Beatles, can be heard at http://www.youtube.com/watch?v=G6-cKpyJ5W4

Note 16. Lecture, "Adverbials, participles and other ing forms in English," delivered November 3, 2004 at the Faculty of Letters and Philosophy of the University of Perugia. For a more in-depth treatment of adverbials and participles in English and German, see Kônig, 1990.

Note 17. For two alternative interpretations of complements used with like and similar verbs, see Bladon (1968) and Duffley (2004).

Note 18. Egan's analysis of the use of the two complements with begin and start concludes that the fundamental difference is that speakers who wish to emphasize the ongoing or unfolding nature of the complement situation tend to use -ing while those who wish to focus on the transitional or starting point of the complement situation tend to use a to+verb form: "A tentative attempt to explain this general tendency might begin by pointing out that all -ing clauses following begin and start, whether they be continuative or iterative, encode a process which has been set in motion and which is continuing to evolve. Whereas an ingressive to infinitive construction may merely mark the starting point of a process, the -ing constructions imply that the process continues unfolding." Egan $(2008,265)$. For other valuable treatments of these aspectual verbs see Duffley (1999), Freed (1979) Dirven (1989) and Conrad (1982). 